\title{
How to Deal with the Concept of Authorship and the Approval of an Institutional Review Board When Writing and Editing Journal Articles
}

\author{
Sun Huh \\ Department of Parasitology and Institute of Medical Education, College of Medicine, Hallym University, Chuncheon, Korea
}

\author{
Corresponding author: \\ Sun Huh \\ Department of Parasitology and \\ Institute of Medical Education, College \\ of Medicine, Hallym University, \\ 1 Hallimdaehak-gil, Chuncheon 24252, \\ Korea \\ Tel +82-33-248-2652 \\ Fax +82-33-256-3426 \\ E-mail shuh@hallym.ac.kr
}

Received: March 2, 2020

Revised: March 9, 2020

Accepted: March 23, 2020
This paper examined the concept of 'authorship,' the 'approval of an institutional review board (IRB),' and the authorship dispute and IRB issues resolution process. Descriptions were based on international guidelines and the literature on research and publication ethics. 'Authorship' entails a promise among co-authors, and as such, outsiders should not be involved. Usually, authorship disputes stem from internal researcher conflict, especially in cases involving the ghost author issue. Qualifying as an author is based on the four criteria recommended by the International Committee of Medical Journal Editors: substantial contributions, drafting the work, final approval, and agreement to be accountable for all aspects of the work. However, these criteria vary according to the academic category. Furthermore, author taxonomy has been introduced to clarify each author's role. Author order also entails a promise among co-authors. The IRB may exempt studies on human subjects or human derivatives that are not related to subjects' safety or do not utilize subjects' personal information from review or from obtaining informed consent. At the core of medical journals' research and publication ethics issues, such as authorship and the IRB's approval, is a commitment to ensuring 'the safety and privacy of subjects and patients.' Given the importance of this principle, research and publication ethics issues are due considerable attention.

(Lab Med Qual Assur 2020;42:63-69)

Key Words Authorship, Bioethics, Personally identifiable information, Research ethics committees, Republic of Korea
This is an Open Access article distributed under the terms of the Creative Commons Attribution Non-Commercial License (http://creativecommons.org/licenses/ by-nc/4.0) which permits unrestricted non-commercial use, distribution, and reproduction in any medium, provided the original work is properly cited.

\section{서론}

대학이나 연구소, 또는 의료기관에 근무하는 많은 보건의료인 은 자료를 정리하고 논문으로 발표하여 다른 연구자와 진료활동을 하는 전 세계 동료에게 도움을 주려고자 한다. 이렇게 논문을 투고 할 때 저자가 고려할 연구출판윤리 사항 가운데, 이 글에서는 '저 자되기(authorship)'와 '기관생명윤리위원회 승인(approval by institutional review board)'에 대해 설명하려고 한다. 구체적 으로 논문을 투고할 때 저자가 주의하여야 할 점이 무엇인지, 또한
편집인은 문제가 발생할 때 어떻게 대처하여야 하는지 기술하려고 한다. 편집인이 문제를 어떻게 다루는지 이해하는 것은 저자도 적 절히 대처하기 위하여 필요하다.

이 연구는 연구출판윤리 사안 가운데 저자되기와 기관위원회 승인 두 종을 집중으로 다룬 기존 지침이나 문헌에 바탕을 두고 분 석 기술한 내용이다. 저자되기는 Lee [1]의 사설을 주로 참조하였 다. 우선 두 가지 용어에 대한 정의를 내리고 국제적으로 통용되거 나 국내법이나 규정에 따라서 시행된 과정을 설명하였다. 그리고 각각의 경우 연구자나 편집인이 접근하는 방향을 제시하였다. 마 
지막으로 문제가 되었을 때 어떻게 처리하는 것이 적절한지 기술 하였다.

\section{Authorship을 우리말에서 어떻게 표현할 것인가}

Merriam-Webster Dictionary에서는 authorship을 "(1) the profession of writing; (2) the source (such as the author) of a piece of writing, music, or art; (3) the state or act of writing, creating, or causing"와 같이 정의한다[2]. 이는 "저작 직업, 원 저작자 출처, 저술행위"로 번역할 수 있으나, 일찍이 전문 가 회의에서 학술지 출판과 관련해서는 "저자됨, 저자되기, 저자 권, 저자표시"와 같이 우리말을 쓰이는 용도에 따라 달리 사용할 것을 제안하였다[3]. 예를 들어 authorship dispute는 저자되기 분쟁, authorship qualification은 저자 자격으로 표기한다.

\section{저자 자격}

이미 잘 알려진 International Committee of Medical Journal Editors (ICMJE) 권고에 따르면 저자가 되기 위해서는 다음과 같은 조건을 충족하여야 한다[4].

(1) 연구구상이나 연구설계에 기여하거나 자료수집, 분석 또는 해석에 참여하였다.

(2) 논문을 작성하거나 중요한 수정에 참여하였다.

(3) 출판 전 최종 원고를 승인하였다.

(4) 논문의 진실성과 정확성에 책임을 진다.

이런 조건을 모두 갖추면 저자 자격이 있다고 할 수 있다. 이 중 에 네 번째 항목은 추후 진실성과 정확성에 문제가 발생할 때 책임 을 진다는 것이므로, 앞에 세 항목과는 달리 투고할 때 필요한 선 언적인 내용이다. 이와 같이 ICMJE 네 가지 저자 자격조건이 널리 활용되고 있지만, 저자 자격조건에 대하여 여러 가지 관행이 존재 한다. 최근 big data를 활용하거나 다기관연구가 활발한 상황에 서 이런 ICMJE 네 가지 기준에 따르면 많은 공저자는 저자 자격이 부족하다고 할 수 있는 경우가 발생한다. 한 예로 입자물리학 분 야에서 저자가 5,000명인 경우이다[5]. 이런 mega-authorship 을 저자 수 남용이며 기여자를 저자로 기술한 적절치 못한 예로 볼 수 있지만, 저자 자격에 대한 기준은 분야마다 또는 학문의 성격 에 따라 차이가 있는 것이 현실이다. 즉 저자 자격에 대한 기준으 로 ICMJE 기준 하나만 있는 것이 아니고, 그 기준을 모든 학술지 가 그대로 따르라는 것은 아니고 편집방침에 따라 개개 논문의 성
격에 따라 편집인이 판단하면 충분하다[6].

\section{저자 역할 표기}

이외에도 저자의 역할을 구체적으로 기술하자는 움직임도 있어 여러 국내•외 학술지에서 이를 도입하였다(Contributor Roles Taxonomy, CRediT; https://casrai.org/credit/). 이 taxonomy에서는 저자 역할을 14 가지로 분류하고 학술지에서 적 절히 도입하여 사용할 수 있도록 나열하였는데, 이것을 논문에 실 제로 기술한 예는 다음과 같다[7].

\author{
Authors' contributions \\ Conceptualization: $\mathrm{SH}$. \\ Data curation: MKY. \\ Formal analysis: EYL. \\ Funding acquisition: $\mathrm{SH}$. \\ Methodology: EYL, MKY, SH. \\ Project administration: $\mathrm{SH}$. \\ Visualization: EYL, MKY, SH. \\ Writing-original draft: EYL. \\ Writing-review \& editing: EYL, MKY, SH.
}

저자 역할은 CRediT에 포함된 여러 항목을 나열할 수 있으 나, writing-original draft, methodology, writing-review \& editing의 세 항목만 나열하여도 부족하지 않다. 또한 저자가 6명 이상인 경우만 각 저자의 역할을 기술하는 것도 편집의 한 방법이 다. 어느 항목을 기술할지는 편집인의 선택에 달려 있다.

\section{교신저자와 첫 저자}

교신저자(corresponding author)와 첫 저자(first author) 의 기준은 무엇일까? 연구자 소속기관에서 저자의 기여도를 평가 할 때 첫 저자와 교신저자의 비중을 높이고 공동저자는 그보다 낮 게 점수를 부여하는 경우도 있기 때문에 연구자에게는 민감한 문 제이다. ICMJE 권고에 따르면 교신저자는 "논문의 투고, 심사, 수 정과정에서 편집인과 의사소통하는 역할을 맡은 저자"이다[4]. 대 개 주관 연구자(principal investigator)가 교신저자를 맡지만, 반드시 그런 것은 아니다. 또한 저자 순서를 정할 때, 이공계열 논 문에서는 논문에 가장 기여도가 많은 사람을 제 1 저자로 하고 최 종 저자는 대개 연장자인 경우가 많다[8]. 그러나 저자 순서는 알 파벳 순서로 할 수도 있고, 기여 정도의 순서로 할 수도 있고, 나이 순 또는 직급순으로 할 수 있으며, 이것은 저자 사이의 약속이다 
[4]. 대부분의 국내 및 국제 학술지에서도 저자 순서기준을 편집방 침이나 투고규정에서 찾기 어려운데, 이는 학술지 편집인 소관 영 역이 아닌 저자 사이 약속이기 때문이다. 국내지에서 학위 논문을 다시 학술지 논문으로 작성한 경우 학위생이 첫 저자로 나가야 한 다고 명시한 예가 있으나 흔히 볼 수 있는 내용은 아니다(https:// kjwhn.org). 첫 저자와 교신저자에게 업적을 더 높게 인정하는 것 은 각 기관의 결정이다. 편집인은 저자 자격 충족 여부를 저자 사 이 약속에 따라 믿고 진행하며 나중에 만약 저자되기 분쟁이 있을 때 상황을 파악하고 결정을 내리는 역할을 하면 충분하다. 그러므 로 편집인은 투고한 원고심사에서 저자 자격이나 저자 수, 저자 순 서에 관여하지 않는다. 저자 수가 100 명이 넘거나 5,000 명이 넘 는 mega-authorship이 존재하는 현실에서 굳이 첫 저자와 공동 저자의 역할을 명백히 구분하거나 자격을 일일이 확인하는 작업은 불가능하기도 하지만 논문의 진실성과 정확성 판단에 큰 의미가 없다[5]. 저자 순서에 무관하게 저자로 목록에 올라가면, 누가 더 많은 책임을 지는 것이 아니고, 논문의 진실성과 정확성에 공동으 로 책임을 진다는 것으로 이해하여야 한다.

\section{저자되기 분쟁}

저자되기와 관련한 분쟁(authorship dispute)은 대개는 공 저자 간 내부 갈등으로부터 일어난다. 연구에 기여하였다고 주장 하는 특정인이 저자 목록에는 없는 'ghost author'의 경우가 가 장 심각하다고 할 수 있겠으나, 법적 소송까지 가지 않는 한은 모 든 공저자의 동의 없는 저자 목록 변경은 영국 Committee of Publication Ethics (COPE) 지침에 따르면 받아들이기 어렵다 [9]. Ghost author를 우리말로 흔히 '유령저자'로 직역하지만, '빠 진 저자'라는 표현이 더 나을 것이다. 특정인이 빠진 저자라고 주 장한다 해도 보수를 받은 경우 용역으로 간주할 수 있는 등 여러 다양한 고려 사항이 있으므로, 저자로 포함시킬지 여부는 공저자 사이에서 결정할 수밖에 없다. 이런 사안은 사전에 서면으로 공저 자로 포함될 것을 약속받은 경우가 아니라면 출판 뒤에 주장하기 쉽지 않다.

$\mathrm{COPE}$ 에서 저자되기 분쟁을 해결하는 도식을 잘 정리하였으므 로 편집인뿐 아니라 저자 역시 이를 참고하여 정확히 이해하는 것 이 필요하다[9]. 그래야만 나중에 저자되기와 관련한 문제가 발생 하였을 때 쉽게 해결책을 찾을 수 있다. 예를 들어, 출판 전 저자 추 가나 삭제는 모든 공저자의 동의를 받으면 가능하다. 출판 후 저자 추가 요청이나 삭제 역시 합리적 이유를 제시하고 모든 공저자가 동의하면 정정기사를 발행할 수 있다. 해결이 복잡한 경우는 출판 후에 저자 사이에 이견이 있을 때이다. 결국 출판 전에 모든 공저 자가 최종 원고에 동의하는 과정을 제대로 거치지 못한 데에서 비
롯된 문제로, 교신저자와 다른 저자 사이의 의사소통에 문제가 있 는 것이다. 현장에서는 이런 요청이 올 수가 있고, 편집인은 양쪽 의견을 모두 편지 형식으로 출판하거나 소수 의견을 따로 출판할 수도 있다. 이러한 상황이 발생하지 않도록 출판 전 저자 사이에 충분히 논의를 마쳐, 논문의 내용에 대하여 출판 후 저자가 이의를 제기하는 일이 없도록 하여야 한다. 특정 저자의 연구부정을 의심 하는 경우 자료 변조가 확실하다면 논문을 취소할 수 있고 확실하 게 밝혀지지 않는 경우에는 우려 표시(expression of concern)를 발행할 수 있다.

편집인이 어떤 논문에 초빙저자(gift author)가 있는지 의심 한다면 해당 저자가 저자 기준을 충족하는지 확인하고, 충족하 지 못한다면 저자가 아닌 기여자(contributor)로 감사의 글에 옮겨 기술하도록 제안하거나 삭제할 수 있다. 이런 과정은 삭제 되는 저자를 포함한 모든 저자로부터 동의를 받은 후 정정기사 (corrigendum)를 출판하는 형식으로 진행한다.

저자가 연구 진실성(research integrity)에 대한 문제가 아닌 한 저자되기 분쟁으로 논문의 철회(withdrawal)를 요청하거나 편집인이 논문을 취소(retraction)하는 것은 COPE 지침에 따르 면 적절하다고 하기 어렵다. 즉 저자되기는 논문 자체의 진실성이 나 정확성의 문제가 아니기 때문이다. 정정기사로 해결하는 것이 COPE 지침이다[10]. 국내에서도 취소기사를 분석한 연구에서 저 자됨을 문제로 취소한 사례는 있으나 이것은 COPE 지침에 따르면 부적절한 취소라고 간주한다[11]. 물론 이런 국제적인 지침이 어 떻든 간에 저자 기여도 문제를 어떻게 취급하느냐는 각 학술지 편 집 정책에 따라 다를 수 있다. 이런 지침은 반드시 지켜야 하는 무 슨 규정이 아니라 단지 전문가가 권장하는 해결방안이기 때문이 다.

\section{저자 소속기관 기술}

저자에 따라 여러 기관에 소속되어 있어서 그 기관을 모두 적을 수도 있다. 연구를 수행한 시기와 논문 발표시기에 저자의 소속이 달라지는 경우, 실제 연구가 진행된 당시 기관을 기재하고 표지 하 단에 현재 저자의 소속기관을 따로 기재하기를 권유하기도 한다. 이런 저자 소속은 저자 본인과 공저자가 협의하여 정하고 기재하 는 것으로, 저자의 기관 귀속 여부를 판단하고 관여하는 것은 편집 인의 소관 영역이 아니다. 물론 해당 연구자가 객관적으로 명백히 엉뚱한 소속을 기술하였다면 확인이 필요하나, 그렇지 않다면 연 구자가 어떤 기관에서, 어느 정도의 기간에, 어떤 일을 했던, 그곳 을 소속기관으로 적는 것은 저자 본인과 공저자의 판단이다. 단지 출판 후 소속에 오류가 있었던 것으로 밝혀질 경우 편집인은 이에 대한 정정기사를 발행할 수 있다. 


\section{기관생명윤리위원회의 연구 승인}

우리나라 '생명윤리 및 안전에 관한 법률(생명윤리법)'에 따르 면 'institutional review board'를 '기관생명윤리위원회(기관위 원회)'라고 표기한다. '생명윤리법' 제7조에 따르면 인간 대상 연 구(사람을 대상으로 물리적으로 개입하거나 의사소통, 대인 접촉 등의 상호작용을 통하여 수행하는 연구 또는 개인을 식별할 수 있 는 정보를 이용하는 연구) 이외에 배아, 인체유래물, 유전자 검사 등이 기관생명윤리위원회의 심의 대상이다[12].

학술지에서 적용한 예로 Journal of Laboratory Medicine and Quality Assurance에 게재된 최근 논문을 살펴보면 "cellfree DNA 정량 측정” 연구에서 환자 또는 정상인의 혈액을 재료 로 사용하였으므로 인체유래물에 해당한다[13]. 그러므로 기관 위원회의 승인이 필요하였다. 물론 이런 측정에 대한 연구는 개 인정보를 노출하지 않고 시행하므로 심의 면제 또는 서면동의(전 자문서를 포함) 면제가 가능하다. 반면 “환자 잔여 혈청을 사용한 prostate specific antigen 측정" 연구는 기관위원회에서 심의 면제를 받았다[14]. 이렇게 한 학술지에서 인체유래물을 사용한 연구에서 기관위원회 승인을 받은 것도 받지 않은 것도 있으므로, 한 학술지에서 연구출판윤리 정책에 맞추어 각 논문에서 기술에 대한 일관성을 유지하는 것이 필요하다. 2020년도 3월 Journal of Laboratory Medicine and Quality Assurance 투고규정에 서 인체 대상 실험에서만 기관위원회의 승인이 필요하다고 기술하 였으므로 인체유래물 연구에서도 반드시 기관위원회의 승인이 필 요한 것은 아니다[15].

생명윤리법은 "인간과 인체유래물 등을 연구하거나 배아나 유 전자 등을 취급할 때 인간의 존엄과 가치를 침해하거나 인체에 위 해를 끼치는 것을 방지"하기 위하여 제정하였다. 그러므로 기관위 원회에서 가장 중요하게 다루어야 하는 것은 "연구 대상 환자 또 는 피험자의 안전과 유전자 정보 등 개인정보의 보호”이다. 최근 모든 자료에서 개인 식별정보는 제외하여 제공하고 후향적 진료 기록부 조사와 같은 연구는 환자안전과 무관하므로 대부분 심의 면제나 서면동의 면제가 가능하다. 반드시 기관위원회 승인과 서 면동의가 필요한 경우는 환자나 피험자 대상 intervention이 필 요한 임상 시험(clinical trial) 등이다. Journal of Laboratory Medicine and Quality Assurance는 정도관리를 다루므로 환자 의 임상 진료정보가 아닌 검체가 주요 연구재료이고, 이런 검체 대 상 연구는 환자안전과는 무관하고 환자의 개인정보나 민감정보가 포함될 여지가 매우 적다. 검사 표준치가 성별, 나이별로 차이가 나는 경우도 성, 나이 정보 이외 다른 진료정보가 포함될 필요가 없으므로 대부분의 경우 기관위원회 심의 면제 또는 서면동의 면 제를 받을 수 있다. 그러므로 Journal of Laboratory Medicine and Quality Assurance 투고규정에서 이 기관위원회 승인에 대 한 기술을 조금더 명확히 한 뒤, 논문의 접수과정에서 이런 관련 부분을 적절히 갖추었는지 전문 원고편집인 또는 학술지 편집인이 사전 점검하는 것이 필요하다.

그런데 이렇게 환자안전과 무관하고 개인정보 포함 여지가 적 은 검체 정도관리 연구에 대해 반드시 기관위원회 심의가 필요한 지 묻는다면, 환자안전이나 개인정보 유출과는 관련이 낮아도 국 내 생명윤리법에 따라 피험자의 안전이나 개인정보 보안에 대한 판단은 기관위원회에서 하는 것이기 때문이라고 답할 수 있다. 개 인을 식별할 수 없는 검체 연구는 기관윤리위원회에서 모두 심의 면제나 서면동의 면제 승인을 받을 수 있으므로 형식적인 절차라 고 무시하지 말고 기관위원회 승인을 받는 것이 필요하다. 국제 학 술지에서는 기관위원회의 심의 여부를 대부분 점검하므로 사전에 심의 받고 승인번호를 포함하여 투고하여야 심사에 들어갈 것이 다. 심의 면제인 경우도 승인번호를 제공하므로 동일하게 제출하 여야 한다. 물론 이런 기준은 국가마다, 학술지마다, 또는 연구자 소속기관의 기관위원회에 따라 차이가 난다.

\section{설문조사 연구에서 서면동의와 기관위원회 동의}

의사소통, 대인접촉을 통한 연구의 예는 인터뷰나 설문조사 연 구이다. 인터뷰에서는 심리, 의학적 문제 등 민감정보를 다룬다면 사전에 서면동의를 받는 것이 필요하며, 그 외 정보를 다룬다고 하 여도 가능하다면 서면동의를 받는 것이 낫다. 물론 모든 설문조사 나 인터뷰에서 민감정보를 다루지는 않는다. 그러나 우리나라 생 명윤리법에 의하면 이것도 사람 대상 연구이므로 기관위원회 심의 대상이다. 기관위원회에서 심의할 때 민감정보나 개인정보를 다루 지 않는 경우 심의 면제를 한다면 연구자는 큰 어려움이 없다. 그 러나 만약 모든 사람 대상 인터뷰나 설문조사에서 서면동의를 요 구한다면 연구자는 어려움을 겪을 수 있다. 그러므로 생명윤리법 에서 서면동의를 면제하는 경우를 아래처럼 기술하고 있다[12].

- 연구 대상자의 동의를 받는 것이 연구 진행과정에서 현실적으 로 불가능하거나 연구의 타당성에 심각한 영향을 미친다고 판 단되는 경우

- 연구 대상자의 동의 거부를 추정할 만한 사유가 없고, 동의를 면제하여도 연구 대상자에게 미치는 위험이 극히 낮은 경우

이 두 가지 경우는 각 기관위원회의 판단에 따르는 것이지 연구 자가 판단할 수 있는 내용이 아니므로 기관위원회 심의 신청할 때 서면동의 면제 사유를 달아야 한다. 웹을 통하여 다중에게 설문응 
답을 요청하여 무작위로 답할 때 성별, 나이, 직업, 거주지 광역행 정구역 등의 정보를 응답자 정보로 수집하는 경우 개인정보가 들 어 있으므로 서면동의를 받아야 한다면 연구자는 온라인 서면동의 를 받으며 진행하는 것이 필요하다.

\section{기관위원회 승인번호가 없지만 환자나 피험 자에게 서면동의 받은 연구출판}

이미 증례보고에서 기관위원회 승인번호 없이 서면동의만 획득 하면 출판 가능한 학술지가 다수 있다. 사람 대상 연구이므로 기관 위원회 심의를 거치는 것이 필요하지만, 출판현장에서는 요구하 지 않는 경우가 많다. 보통 증례보고에서 서면동의가 필요하지 기 관위원회 승인까지 언급하지 않는다[16]. 서면동의는 식별 가능한 사진이나 그림을 발표할 때 필요한데, 영상자료도 식별 가능한 자 료라고 간주한다. ICMJE에 따르면 익명성을 지키는 데 조금이라 도 의문이 가는 경우 서면동의를 받아아 한다[17]. 증례보고에서 인체 사진 노출이 있는 경우 비록 얼굴 부위가 아니고 식별 가능하 지 않다고 하더라도 서면동의 받는 것이 바람직하다. 환자 본인이 나 가족이라면 알아볼 수 있기 때문이다. 또한 학술지 정책에 따라 X-ray 등 영상자료의 서면동의를 요구하는 곳도 있다. 환자나 환 자 가족과 연락할 수 없어서 서면동의를 도저히 받을 수 없는 경우 기관위원회에 사유를 설명하고 면제를 받아서 출판할 수 있다.

\section{설문조사에서 서면동의를 받은 연구는 기관 위원회 승인번호가 없어도 투고가 가능할까?}

국내 생명윤리법에서는 설문조사도 사람 대상 연구이므로 기관 위원회 승인을 받아야 한다고 하며, 이는 피험자 안전을 고려하여 서면동의가 필요하기 때문이다. 그러나 설문조사는 학술지 편집 정책에 따라 반드시 기관위원회 승인번호를 요구하지 않고 증례 보고처럼 서면동의만 있으면 투고 가능한 경우도 있으니, 투고하 고자 하는 학술지의 정책을 세심히 살펴볼 필요가 있다. 대부분 국 내•외 의학 학술지에서 인체 대상이거나 인체유래물을 다루는 모 든 투고논문에 대해 기관위원회 심의번호와 서면동의를 동시에 확 인하거나 최소 둘 중 하나를 확인하고 설문조사도 해당하므로 이 런 윤리사항을 연구자가 사전에 잘 파악하고 적절히 준비하여야 한다.

\section{기관위원회에서 다룬 연구 대상 변화}

우리나라는 임상시험 연구(clinical trial/study)를 심의하 기 위하여 1995년 임상시험관리기준(Korean Good Clinical
Practice)이 도입되기 전까지, 대한의사협회에서 헬싱키선언을 준수하도록 권장한 지침 외에는 관련 규정이 없었다. 의약품 임상 시험관리기준은 1995년 10월 1일부터 시행되어 임상시험심사위 원회(심사위원회, institutional review board)의 설치를 의무화 하여 피험자 안전을 확보하는 목적으로 주로 의료기관에서 심사위 원회를 두고 심의하기 시작하였다[18]. 이 심사위원회는 임상시험 을 다루는 것이 목적이었으므로 임상시험이 아닌 경우도 심의 대 상으로 삼을 수는 있으나 반드시 심의가 필요한 대상이 아니었다.

또한 2004년 생명윤리법 제정 및 공포 이후에 모든 교육기관에 서 기관위원회를 설립 운영하기 시작한 것은 아니었다. 그 이유는 인간대상 연구와 인체유래물 연구를 포함시킨 2012년 개정 전까 지는 인간의 배아, 세포, 유전자를 다루는 생명과학기술이 심의 대 상이었기 때문이다. 설치 의무기관도 배아생성의료기관, 배아연구 기관, 체세포복재배아연구기관, 유전자검사기관, 유전자은행, 유 전자치료기관에 한정되어 있었다. 2012년부터 기관위원회 설치 의무기관이 전문연구기관, 대학, 의료기관, 기업연구소 등 모든 인 체와 인체유래물 연구기관으로 확대되어 2013년부터 대부분의 대학이나 의료기관에서 기관위원회를 설립 운영하기 시작하였다 [19]. 즉 2012년까지는 비록 기관위원회가 설치 되었다고 하더라 도 인체 대상 연구나 인체유래물 대상은 심의 대상이 아니어서 대 학인 경우 승인번호를 받을 방법도 없었다.

법률에서 정한 것이 아니므로 2012년까지는 대학에 기관위원 회를 설립하지 않았고, 또한 의료기관의 심사위원회에서도 의약품 임상시험관리기준에 심의대상이 아닌 인간 대상 연구를 같이 심의 대상으로 다루지 못하였기 retrospective chart review인 경우 심의 신청을 아예 못하였을 수도 있다.

\section{기관위원회 승인 후 연구 대상이나 방법 수정}

논문을 발표한 뒤에 편집인에 따라서 어떤 논문의 진실성이나 정확성에 대하여 저자에게 의문을 제기하고 기관위원회의 의견을 요구할 때가 있다. 연구자가 기관위원회에 제출한 계획서에서 일 부 대상자 수집방법을 수정하여 연구를 진행할 때 일일이 수정을 보고하지 않을 수 있기 때문이다. 이 경우 기관위원회에서는 연구 결과가 처음 제출한 계획서와 다르다고 연구계획서를 적절히 수정 하지 않은 귀책 사유를 들어 연구자가 수행한 연구결과는 기관위 원회 승인받지 않았다고 편집인에게 답할 수 있다. 대상자를 중복 하여 사용하는 경우는 방법에서 어느 연구에서 이미 대상으로 분 석한 자료를 중복하여 포함시켰다고 기술하는 것이 필요하다. 그 러므로 기관위원회 승인받은 후에라도 대상이나 방법에서 연구결 과에 영향을 미칠 수준의 변경사항이 있는 경우, 가능하다면 수정 보완을 하는 것이 필요하다. 즉 사유서와 함께 '연구계획변경 심의 
신청서'를 제출하여 승인을 받아야 추후 발생할 수 있는 논란의 여 지를 없앨 수 있다.

또한 이런 대상자나 자료 자체를 명확하게 하고 추후 재현성 등 에 대한 논란의 여지를 없애기 위하여 많은 학술지가 자료 제출을 심사과정에 요청하기도 하거나 아예 자료공유(data sharing)을 요청하기도 한다. 비록 이런 것이 필수가 아니라도 투고할 때 자료 를 제공한다면 중복출판 사안으로 추후 문제가 되는 것을 막을 수 있을 것이다[20].

\section{연구출판윤리의 시효}

위에 언급한 기관위원회 승인 사안은 시간이 지나면서 기준이 변경된 경우라고 볼 수 있으므로, 가능하다면 검증시효를 5년으로 정하고 그 이전의 사안은 환자안전이 개인정보 보호에 문제가 없 다면 연구출판윤리에서 굳이 다루지 않는 것도 고려할 수 있다. 하 지만 이 시효가 과거에는 5년으로 존재하다 "연구윤리 확보를 위 한 지침” 2011년 6월 개정판에서 사라졌다[21]. 그렇다고 만일 지금 과거에 기관위원회 승인 여부를 허위로 작성한 논문을 모두 찾아내는 작업을 한다면 결국 지금의 잣대로 과거를 재단하게 되 는 것이다. 당시 우리 학문 사회가 처했던 실정에 대한 일말의 고 찰 없이 현재 기준을 적용한다면 공정하다고도 하기 어렵다. 2005 년까지 국문지에 국문 논문을 발표한 후 이를 국제지에 다시 영 문으로 번역하여 투고하는 것이 일부 의학분야 젊은 연구자의 숙 제이자 업무이기도 한 예가 있다. 언어가 다르고 독자가 다르므로 이차출판이라는 사실을 밝히면서 투고할 수 있다는 개념을 정확 히 파악하지 못하고, 훈련과정에서 학습한 적도 없으며, 국내지가 PubMed에서 검색되지도 않으므로 벌어진 일이다[11].

\section{시대에 따른 윤리 변화}

윤리가 무엇인지 정의하는 것이 어렵지만, 우리 사회의 관습, 도 덕기준이라고 말할 수 있다면 이 윤리는 특정한 불변의 잣대로 절
댓값을 부여할 수 있는 것이 아니라 세월이 지나가면서 시대의 환 경이나 요구에 따라 계속 변화함을 이해하여야 한다. 우리가 지금 믿고 실천하는 윤리가 10년이나 20년, 30년 후에 윤리 위배행위 로 논란이 된다면 현재 자신감과 확신을 가지고 할 수 있는 일은 많지 않을 것이다. 명백한 답이 있는 것이 아닌 윤리와 관련된 사 안은 시대와 지역, 집단에 따라 차이가 나는 것이고 계속 진화하므 로, 특정 전문가 집단의 잣대로 다른 집단을 판단하거나 현재의 잣 대로 과거를 판단하는 것은 매우 위험할 수 있다. 윤리는 특정 시 대, 특정 집단에서 공유하는 상식이지 절대적인 기준이 있는 것이 아니기 때문이다.

\section{결론}

저자 자격은 공저자 사이의 약속이므로 외부에서 관여할 수 있 는 내용이 아니다. 대개 저자되기 문제는 내부에서 일어나는데 특 히 ghost author(빠진 저자) 문제가 발생할 때 논란이 된다. 저자 자격은 ICMJE의 네 가지 조건에 해당하는지를 판단하여 정하는 것을 권장하기도 하지만, 이 저자 자격은 여러 관행이 있으므로 편 집인이 학술지 성격에 맞추어 정하면 충분하다. 저자 순서는 공저 자 사이 약속이다. 검체를 대상으로 하고 환자나 피험자 안전이나 개인정보와 관련이 적은 경우 대부분 기관위원회 심의면제 또는 서면동의 면제를 받을 수 있다. 저자되기 문제나 기관위원회 승인 등 의학학술 논문 연구출판윤리 사안에서 가장 중요하게 고려할 것은 “피험자와 환자의 안전과 개인정보 보호"이다. 이런 점을 바 탕으로 연구윤리 사안을 판단하고 실천하면 충분하다.

\section{CONFLICT OF INTEREST}

Sun Huh is the 9th President of the Korean Association of Medical Journal Editors (April 1, 2020 to March 31, 2022). Except for that, no potential conflict of interest relevant to this article was reported.

\section{REFERENCES}

1. Lee RA. For the appropriate authorship in medical journal. Ewha Med J 2019;42:49-55.

2. Merriam-Webster Dictionary. Authorship. https://www.merriam-webster.com/dictionary/authorship (Accessed February 29, 2020).

3. Hahm CK. The terminology of scholarly journal editing in the 9th round table discussion for medical terminology. https://www.namok.or.kr/bbs/index.html?code=conference\&category=\&gubun=\&page=3\&number=687\&mode=view \&keyfield=\&key= (Accessed February 29, 2020).

4. International Committee of Medical Journal Editors. Defining the role of authors and contributors. http://www. 
icmje.org/recommendations/browse/roles-and-responsibilities/defining-the-role-of-authors-and-contributors.html (Accessed February 29, 2020).

5. Aad G, Abbott B, Abdallah J, Abdinov O, Aben R, Abolins M, et al. Combined measurement of the Higgs boson mass in pp collisions at sqrt[s]=7 and $8 \mathrm{TeV}$ with the ATLAS and CMS experiments. Phys Rev Lett 2015;114:191803.

6. National Academies of Sciences, Engineering, and Medicine. Fostering integrity in research. https://www.nap.edu/ catalog/21896/fostering-integrity-in-research (Accessed March 9, 2020).

7. Lim EY, Yim MK, Huh S. Smart device-based testing for medical students in Korea: satisfaction, convenience, and advantages. J Educ Eval Health Prof 2017;14:7.

8. Han DS. Good publication practice guideline for medical journals. https://www.kamje.or.kr/ (Accessed March 9, 2020).

9. Committee of Publication Ethics. Flowcharts. https://publicationethics.org/guidance/Flowcharts (Accessed February 29, 2020).

10. Committee of Publication Ethics. Retraction guideline. https://doi.org/10.24318/cope.2019.1.4 (Accessed February 29, 2020).

11. Huh S, Kim SY, Cho HM. Characteristics of retractions from Korean medical journals in the KoreaMed database: a bibliometric analysis. PLoS One 2016;11:e0163588.

12. Ministry of Government Legislation of Korea. Bioethics and Safety Act. http://www.law.go.kr/main.html (Accessed February 29, 2020).

13. Jeon K, Lee J, Lee JS, Kim M, Kim HS, Kang HJ, et al. Quantification of cell-free DNA: a comparative study of three different methods. J Lab Med Qual Assur 2019;41:214-9.

14. Choi WK, Kim HK, Lee W, Chun S, Min WK. Performance evaluation of the total prostate-specific antigen (PSA), free PSA, and [-2]proPSA assay for calculation of the Prostate Health Index using the UniCel Dxl 800 analyzer. J Lab Med Qual Assur 2019;41:207-13.

15. Korean Association of External Quality Assessment Service. Instructions for authors. http://www.jlmqa.org/for/ sub01.html (Accessed February 29, 2020).

16. Huh S. Protection of personal information in medical journal publications. Neurointervention 2019;14:1-8.

17. International Committee of Medical Journal Editors. Protection of research participants. http://www.icmje.org/ recommendations/browse/roles-and-responsibilities/protection-of-research-participants.html (Accessed February 29, 2020).

18. Ministry of Food and Drug Safety. Clinical trial management criteria for medicine. http://www.law.go.kr/LSW/ admRullnfoP.do?admRulSeq=4372 (Accessed February 29, 2020).

19. Park HW. Effect of Bioethics and Safety Act in medical research. J Korean Med Assoc 2013;56:665-75.

20. Kim SY, Yi HJ, Huh S. Current and planned adoption of data sharing policies by editors of Korean scholarly journals. Sci Ed 2019;6:19-24.

21. Ministry of Education. Guideline for Research ethics. http://www.law.go.kr/LSW/admRullnfoP.do?admRulSeq= 2000000016351 (Accessed February 29, 2020). 